\title{
Editorial Towards a Universal Basic Income?
}

Jennifer Lehmann and Rachael Sanders

In the last issue of Children Australia, we discussed the concerning impacts of failing social security systems on families with children and young people in their care. The continual reports of difficulties accessing income supports are contributing to poverty in Australia and elsewhere in spite of extreme poverty having decreased on a global basis (Roser \& Ortiz-Ospina, 2018). In addition, there is ample anecdotal evidence of the frustrations and difficulties experienced when trying to access income support.

For some decades, various countries, including the USA, have proposed a universal basic income (UBI) approach to alleviating poverty and disadvantage with mixed responses. As we enter a new era of static wages in many developed countries (Commonwealth of Australia, 2017a), and changes in the nature and availability of employment due to technological change amongst other issues (Gerard, 2018; Straubhaar, 2017; United Nations, Economic and Social Commission for Asia and the Pacific, 2018), there is again the impetus to investigate and consider the implementation of some form of UBI, not only in other nations of the developed world, but also in Australia.

But what is a UBI? There are various forms of UBI that have been proposed which Arthur (2016) summarises. UBI approaches have been trialled on at least five occasions (Arnold, 2018), these being carried out in several different locations and therefore in differing cultural milieus: Canada (Ontario and Mincome trials), Kenya, Finland, and California (Stockton).

The full UBI approach, which is somewhat utopian, sees every citizen in the country receives an income automatically, and equity is obtained through a taxation system that targets high-earning companies and individuals. It is described by Straubhaar (2017, p. 74-75):

The UBI is an unconditional cash payment that flows monthly from the state budget to everybody. It is transferred from public to private accounts throughout an entire lifetime, from birth to death, without any application or preconditions to be fulfilled by the beneficiary. It is supposed to cover the socio-cultural subsistence minimum. However, the determination of this minimum level of subsistence is a political and not an economic decision. The UBI is guaranteed to each member of society as an individual legal claim. It flows independent of employment, personal circumstances, relationships or attitudes. No one checks who is living with whom in what kind of relationship or whether there are good or bad reasons for granting a minimum allowance.

This form of UBI is considered a replacement for all other welfare-related payments, thus negating the need for multiple forms of income support and assessment against complex criteria, though some additional funds are usually available for cases of disability. Describing the proposal made by Rhys Williams back in the 1940s, Straubhaar (2017, p. 75) indicated that Williams wanted to dispense with citizens having to prove eligibility for income assistance saying that 'the abolition of a degrading "petition" and the distrustful control by state authorities were the decisive advantages of ensuring citizens' livelihoods without preconditions'. This approach to a UBI is claimed to be effective and efficient in redistribution, saving significant costs in the provision of welfare, enabling all citizens to have purchasing power, and ensuring that those who generate wealth through companies or employment are taxed appropriately. There is always an incentive to gain employment where this is possible, but there is no shame in being unemployed as it is understood that not all citizens have the capacity or access to jobs in the changing economy.

Concerns about the establishment of this form of UBI focus predominantly on the significant change to the current emphasis placed on participation in employment, and the belief that people will no longer contribute to the economy through work if they receive an income enabling them to live without poverty (Arthur, 2017). This is not supported by evidence according to the Psychologists for Social Change organisation (2017), which assessed the several trials that have been, or are being held. The recently established scheme in Kenya follows this form of UBI, though it is about $1 / 4$ to $1 / 2$ of average income that is paid to all Kenyans, and there is no evidence that work is not being sought by those able to hold down employment. 
Because of concerns that people won't seek work if they receive a UBI means testing has been proposed as an alternative model. This approach is based on income, rather than on the reasons for not participating in paid work. The 1970s Mincome Trial in Canada was based on this model and believed to have a marked effect on keeping young people at school, thus qualifying them for employment that they otherwise would not have gained. The more recent Ontario trial was also of this nature and was set up with key criteria for evaluation (Ministry of Children, Community and Social Services, 2018) through which it was hoped to show that the health and welfare benefits to families and children would be significant. The Canadian UBI trial is, sadly, to be terminated in March 2019 due to the decision of the recently elected conservative government, and after only one year of the three years proposed (Arnold, 2018), thus limiting any evaluation of 'success'. Indeed, one of the difficulties with any form of UBI or guaranteed income trial is that outcomes tend to be long term and most trials have been far too short to be sure of permanent benefits to participants.

A focussed and more limited UBI that has been considered is one that can be applied for by those who are unable to work or to obtain employment for reason of ill-health, age, disability, or lack of employment available within a reasonable distance to place of residence. This is close to the current Australian social security (Centrelink) system in which people must demonstrate both their circumstances to meet eligibility criteria, together with their lack of income, rather than payments being based on their earnings alone. However, this model of UBI does have the advantage of providing the same level of income to those participating rather than differing payments according to the nature of the reason for not being able to gain employment as is currently the case. This is not a model favoured by supporters of a UBI system.

A variety of criticisms and fears have been expressed about the UBI approach with cost being one of the greatest concerns (United Nations, 2018). Many of these fears are based on prejudices, according to Dunlop (2018), such as those associated with beliefs that a UBI will result in people refusing to work, and, more particularly, that people in poverty are more likely to be addicted to drugs and alcohol, to gamble, and to neglect or abuse their children. Addictions may have some correlation with living in poverty in the light of the disadvantage, despondency, and frustrations being in poverty entails. However, this point of view overlooks the fact that many income earning people are drug users, drink to excess, gamble, are abusive in the home environment, and disadvantage their children, and there is no evidence to date to show that an increased income to those who would otherwise live in poverty leads to greater abuse of drugs or gambling (Psychologists for Social Change, 2017).

Countering the criticisms, there are those who believe that fundamental positive change will occur if people have access to a UBI. The Psychologists for Social Change
(2017, n.p.) stated that results from UBI experiments indicate:

...improved physical and mental health and a reduction in hospital admissions; reduced stigmatisation of those on low incomes; positive impact on the social standing of women, especially those on low incomes; continued commitments to paid employment; empowerment of women; and increased life satisfaction and happiness of those in receipt of payments.

There are, of course, also stories of people who break free of poverty through the financial dividends of UBI-like payments. For instance, the story of Skooter McCoy and his family (Lapowsky, 2017) describes the impacts of receiving regular payments as a result of the Eastern Band of Cherokee Indians' decision to set up a casino with profits shared between all local indigenous community members.

It is difficult to counter the argument of impossible costs of a UBI which would require substantial changes to both welfare and tax systems, as well as various subsidising arrangements for such services as child care. However, Stevens and Simpson (2017) argued strongly that poverty would be significantly reduced in Canada with the introduction of some form of UBI. One needs to take account of current expenditure and how much of this would be eliminated, plus assess the likely associated benefits to health, nutrition, housing, and so on. In Australia, it is difficult to grasp the details of expenditure on administration of, and payments for, income support for the 19-odd categories of income support. The total budget for the 2018-19 Financial Year for the Department of Social Services is estimated to be $\$ 113,885,615,000$ (Commonwealth of Australia, 2018), while some 34,037 people were employed by the Department in the 2016-17 financial year with a departmental appropriation of $\$ 4,269,324,000$ for its operations (Commonwealth of Australia, 2017b). It cannot be assumed that all of this expenditure would be eliminated. The establishment of a UBI would alter other expectations too - for university students, carers, and for recipients of 'care packages' and in all likelihood to superannuation arrangements for which huge sums are currently accumulated. However, to counter some of the concerns, there may be the benefits of greater participation in economic activity with the introduction of a UBI with increased spending power and choice, along with other factors difficult to estimate or predict.

In spite of the difficulties inherent in the fundamental changes that any form of UBI would precipitate, there are clearly some benefits to family life, children, and young people of an increased and stable income (Gennetian, Castells, \& Morris, 2010; Gerard, 2018). Forget (2011) was able to evaluate a number of factors in the Mincomb trial [Canada] and found

an 8.5 percent reduction in the hospitalization rate for participants relative to controls, particularly for accidents and injuries and mental health. ... [and] also found that 
participant contacts with physicians declined, especially for mental health, and that more adolescents continued into grade 12. (p. 283)

The health aspects of these findings are concomitant with those of Beck, Pulkki-Brännström and San Sebastián (2015, p.123), who evaluated a basic income trial in rural India which 'led to a reduction in the incidence of illnesses and injuries not requiring hospitalisation.' These findings go some way to support our contention in our previous Editorial (Lehmann, Lehmann, \& Sanders, 2018) that a UBI would contribute to beneficial outcomes for low-income families and their dependents. In addition, we maintain that dealing with a somewhat combative system to gain income support is unhelpful to parents' wellbeing and, consequently, to that of their children. In addition, the nature of negotiating one's way through social security systems means that some people just give up and live in abject poverty, some become angry and fearful, creating an emotionally-charged atmosphere that affects their offspring, while others somehow manage to obtain payments and live on income support that is inadequate and maintains them in a state of poverty — and with that the culture of poverty is also passed on to their children. Perhaps in this rapidly changing world, we need to be much more proactive with regard to the alleviation of poverty and take steps to reduce the ever-growing gap between those with wealth and those without. Civil unrest on account of not having fair access to an adequate income, and the resources that flow from this, will do our next generation no favours either.

The final issue for 2018 begins with three opinion pieces by women who are experts in their respective fields of study. These opinion pieces are prompting us to reflect on the legitimacy of certain social norms and systemic practices that potentially impact negatively on the lives of children. Nicola Atwool from the University of Otago, New Zealand (NZ), has raised the pertinent question, 'Are we setting children in care and their caregivers up to fail?' Nicola discusses some of the common challenges faced by the out-of-home care system, such as inadequate support for caregivers, an insufficient number of foster carers, inadequate training for foster parents on the nature of trauma, and the resources available to maintain and promote cultural connection for Indigenous children. While Nicola is thinking about these issues within an NZ context, they appear to be common challenges faced by out-of-home care systems worldwide. Given these and other challenges, Nicola says we need a large enough pool of caregivers to be able to match children to the most appropriate caregivers for their circumstances and that these placements must then be well supported. Without this, she says, we will continue to set children and caregivers up to fail.

Julie Edwards from Jesuit Social Services raises the issue of young people's experience of the criminal justice system. Julie questions the appropriateness of some system and legislative responses to children who have entered the criminal justice system, particularly for children under the age of 14 years. She states that some system responses are causing more harm and she advocates a greater focus on prevention and addressing the underlying causes of crime, particularly the social and economic disadvantage that impacts on individuals, families, and communities. For those young people who do enter the youth justice system, she is campaigning for a greater commitment to rehabilitation to ensure that children are provided with better outcomes as they exit the system, hopefully permanently.

Pamela Schulz has provided a thorough and thought provoking opinion piece on the various ways in which children and childhood can be viewed in contemporary Australia and internationally. She discusses the ways in which children are potentially used as a commodity, a way of showcasing good parenting, or even as a measure of societal values and opportunities. She discusses and challenges the ways in which children are portrayed in the media and ruminates on the possible implications this can have on children and choices made by parents.

This issue also includes four research articles covering a range of topics. We begin with a paper by Stacey Alexander, Margarita Frederico, and Maureen Long who undertook research examining Early Childhood Intervention professionals' knowledge and application of attachment theory in their practice. The professionals who participated in this study reported that they view attachment as very important and that part of their role is to promote good attachment as a way of improving children's learning and wellbeing. They also found that fewer than half of the participants had learnt about attachment in their undergraduate training, but most learnt 'on the job'. In spite of the knowledge deficits in training, however, they found just over half of the participants were comfortable with addressing attachment concerns with families.

Still on the topic of childhood trauma, but this time from the perspective of children, Rebecca Fairchild and Katrina McFerran report on their study of children's personal resources and capacities in times of crisis. Based on a participatory arts-based research project with pre-adolescent children, the investigators explored children's personal resources and the ways in which they can help improve their lives. Among the most common resources named by children as helping them to do well in their lives were friends, family, sport, pets, journaling, hope, and creativity. They found that these resources helped children in various ways when seeking safety and when thinking about their future, and that it is important to foster and build upon their personal resources. Moreover, a key feature of this study is to highlight the value and importance of giving children a voice through participatory processes.

Alhassan Abdullah, Ebenezer Cudjoe, and Margarita Frederico undertook a study with child protection workers in Ghana. Having identified very little empirical evidence about the barriers to children's participation in child protection matters in Ghana, they sought the opinions and 
experiences of child protection workers about the barriers they see that prevent children's participation in child protection processes. The participants said that intimidation, parental influence, communication problems, and confidentiality were common barriers faced by children that prevented them from full and transparent participation in the service. The authors recommend strategies that are commonly employed within Australia and elsewhere, such as engaging children in separate rooms or sites without the presence of parents, and for practitioners to upgrade their skills in working with children to aid in communication. While their practice recommendations are already in place in Australia, this study highlights issues of cultural difference and promotes further consideration of this for practitioners who work with families from diverse cultures.

Examining a very different topic, Sylvia Ruocco, Nerelie Freeman, and Louise Mclean have produced a new pictorial Child Anxiety and Coping Interview (CACI). Their study measures the efficacy of the CACI in eliciting children's self-report of problems, emotions, coping strategies, and coping self-efficacy. They found that the five most common problems reported by children are fear of spiders or insects, fear of the dark, going places without parents, doing badly at school, and heights. The five most common coping strategies conveyed by the children were supportseeking, behavioural avoidance, solving the problem, facing the challenge, and behavioural distraction. This study indicates that children are able to provide a self-report of their anxiety problems, coping strategies, and emotions, and that the CACI can help identify helpful coping behaviours that can be supported, as well as less effective coping strategies that would benefit from intervention.

We would like to send our thanks and appreciation to the authors, reviewers, and editorial consultants who contributed to the journal in 2018. We would also like to send our warm wishes to readers of the journal for the festive season and hope that 2019 brings many more opportunities for the generation of knowledge and learning through Children Australia.

\section{References}

Arnold, C. (2018). Money for nothing: The truth about universal basic income. Nature, 557, 626-628. doi: 10.1038/d41586-018-05259-x. Retrieved from https:// www.nature.com/articles/d41586-018-05259-x

Arthur, D. (2016). Basic income: A radical idea enters the mainstream. Research Paper Series. Canberra: Parliament of Australia. Retrieved from http://parlinfo.aph.gov.au/ parlInfo/download/library/prspub/4941916/upload_ binary/4941916.pdf.

Beck, S., Pulkki-Brännström, A., \& San Sebastián, M. (2015). Basic income - healthy outcome? Effects on health of an Indian basic income pilot project: A cluster randomised trial. Journal of Development Effectiveness, 7(1), 111-126. doi: 10.1080/19439342.2014.974200
Commonwealth of Australia (2017a). Analysis of wage growth: November 2017. Canberra: The Treasury. Retrieved from https://static.treasury.gov.au/uploads/sites/1/2017/11/ p2017-t237966.pdf.

Commonwealth of Australia (2017b). 2016-17 Annual Report. Canberra: Department of Human Services. Retrieved from https://www.humanservices.gov.au/sites/default/files/ 2017/10/8802-1710-annual-report-2016-17.pdf.

Commonwealth of Australia (2018). Budget 2018-19: Portfolio Budget Statements 2018-19 - Budget Related Paper No. 1.11: Human Services Portfolio. Canberra: Department of Human Services. Retrieved from https://www. humanservices.gov.au/organisations/about-us/ budget/budget-2018-19.

Dunlop, T. (2018). The future of everything: Big, audacious ideas for a better world. Sydney: New South Publishing/University of NSW.

Forget, E. (2011). The town with no poverty: The health effects of a Canadian guaranteed annual income field experiment. Canadian Public Policy, 37(3), 283-305. doi: 10.1353/cpp.2011.0036

Gennetian, L., Castells, N., \& Morris, P. (2010). Meeting the basic needs of children: Does income matter? Children and Youth Services Review, 32, 1138-1148.

Gerard, N. (2018). Universal healthcare and universal basic income: Complementary proposals for a precarious future. Journal of Health Organization and Management, 32(3), 394-401. doi.org/10.1108/JHOM-01-2018-0004

Lapowsky, I. (2017, December 11). Free money: The surprising effects of a basic income supplied by government. Wired. Retrieved from https://www.wired.com/story/freemoney-the-surprising-effects-of-a-basic-income-supplied -by-government/.

Lehmann, C., Lehmann, J., \& Sanders, R. (2018). Missing out: The intergenerational ramifications of current social security arrangements. Children Australia, 43(3), 163-168.

Ministry of Children, Community and Social Services (2012-2018). Ontario basic income pilot. Retrieved from https://www.ontario.ca/page/ontario-basic-income-pilot

Psychologists for Social Change (2017). Universal basic income: A psychological impact assessment. London: Psychologists Against Austerity. Retrieved from http://www. psychchange.org/uploads/9/7/9/7/97971280/ ubi_for_web_updated.pdf.

Roser, M., \& Ortiz-Ospina, E. (2018). Global extreme poverty. OurWorldInData.org. Retrieved from: https://our worldindata.org/extreme-poverty

Stevens, H., \& Simpson, W. (2017). Toward a national universal guaranteed basic income. Canadian Public Policy. doi:10.3138/cpp.2016-042.

Straubhaar, T. (2017). On the economics of a universal basic income. Intereconomics, 52(2), 74-80. doi: 10.1007/ s10272-017-0649-8. Retrieved from https://link.springer. com/article/10.1007/s10272-017-0649-8

United Nations Economic and Social Commission for Asia and the Pacific (2018). Universal Basic Income, MPFD Policy Briefs, 66, 1-3. Retrieved from https://www.unescap. org/resources/mpfd-policy-brief-no-66-universal-basicincome 